\title{
Human Ecological Analysis of the Life of Pi
}

\author{
Man Bahadur Khattri
}

\begin{abstract}
In this article, Ihave discussed how can we analyze an adventurous and fantasy Novel like "Life of P $i$ " from human ecological perspective. Knowledge is generated and applied in diverse spatial and temporal contexts, which has varied implication to individuals, households, communities, and human kind as a whole. The implication confines not only to human being would be equally implicate to the surrounding of biotic and abiotic elements. The human ecological knowledge of "Life of P $i$ " is one of such case. The early life of Mr. $P i$ and his social educational background had great implication on his later academic life, thinking, acting and feeling as well as for livelihood. How diversity plays a great role in our perception and creates beautify of life around us? The difference between 'knowing how' and 'knowing that' is felt by people of different socioeconomic background. Knowing how is more relevant in the context of practical or empirical knowledge. Knowing that is a formal informed knowledge with little connotation of empirical understanding. Combination of both types of knowledge is important in human ecological analysis. In this article I have tried to explore complex connectivity in relation with human being, diverse animal's world, and landscape relation from human ecological perspective which can be vividly locate in the Novel.
\end{abstract}

Keywords: Richard Parker, Booker Prize, phronesis, knowing that, knowing how 


\section{6| Man Bahadur Khattri}

\section{Introduction}

In this article I have focused on the question how social, cultural, religious, and environmental contexts effect an individual's understanding and acting in the global world. Reading the fantasy Novel "Life of Pi", I have looked on the point that how Yann Martel of his multicultural interaction and understanding, curiosity and empirical knowledge has contributed to write Novel, "Life of Pi". The Novel is successful to give us insight on the importance of diverse religious values and philosophy, need of bio-diversity protection and importance of conserving socio-cultural diversity. Though the "Life of Pi" is a fiction, epistemologically it is associated with philosophy, theories and practices of eco-systemic diversity of the world. The fiction has been analyzed and linked with broadly Indian sub-continent and Hindu practices-a way of life in relation with flora and fauna that ultimately supports conservation of bio-diversity, protection of environment, and the issue of global climate change. In this article I focus on the issue of conservation and sustainable use of bio-diversity. This issue is very clearly presented in "Life of Pi" by Yann Martel (2001) using most powerful and humanistic expressions, which has great influence to the common people's perception. People around the world live in different ecological settings and have accumulated knowledge on the basis of their experiences in relation to their survival that supports to acknowledge the biological diversity. Therefore, I argue that without conserving or respecting people of different cultural background conservation of biological diversity is not possible all around the world. Knowing how is context specific, empirical and dynamic knowledge and deserves special importance because it informs us the dynamic aspect of human-environment relation with concrete evidence and gives way out to the problems which is key areas human ecology.

\section{Summary of Book: Life of Pi}

First, I would like to summarize briefly the Novel, "Life of Pi" written by Yann Martel. In this section I would like to focus on major events described by author. The "Life of Pi" is an extraordinary English novel that shows the relationship among human being, animals, land and water. The Novel is structured in three parts, 100 chapter and 319 pages. The First part is in Toronto and Pondicherry which consists 


\section{7| Man Bahadur Khattri}

total 36 chapters. Second part is in the Pacific Ocean which is the most voluminous that starts from 37 ends at 94 chapters. The last part is about Benito Juarez Infirmary, Tomatlan, Mexico which starts from 95 ends at 100 chapters. In this Novel Mr. Pi or Piscine Molitor Patel, an Indian origin middle-aged man who lives in Canada is the main character and used to express opinions and arguments. The author is telling story of $\mathrm{Mr}$. Pi "in his voice and through his eyes". It seems to be "Mr. Pi's story". However, we should keep in mind that the author has used almost the same stand to Richard Parker, the Bengali tiger which survived in shipwrecked and reached to Mexican forest as personhood to non-human person. Therefore, the Novel is also about Richard Parker, or endangered animal of the world.

"Life of Pi" was published in 2001 as a fantasy adventurous Novel. Mr. Pi and the Richard Parker, a Bengali Tiger, the main character were stranded in a lifeboat in the Pacific Ocean for 227 days. Beside these two there were some other wild animals: a hyena, a zebra, an orangutan, a rat and cockroaches. The Novel tells retrospect story in India, in the Pacific Ocean and in Mexico. The First chapter begins with the introduction of Mr. Pi's life in Canada, education and his excellence awards. Mr. Pi had majors in Zoology and religious studies. He further remembers his life in Mexico and people's loved him. At the same time he has mentioned that he used hand for eating even in a restaurant in Canada. The more reference characters for the story are his brother Ravi, his parents and mamaji (the guru/teacher of Pi for swimming and great storyteller). They had nick name for mamaji, "Mr. Fish". Mr. Pi was named after a swimming pool Piscine in Paris. His father was a business man, he run a large hotel in Madras, later he moved to Pondicherry to the zoo business. Since his childhood Mr. Pi was wondering about God. He had multi religious social setting since his childhood. His house was itself a study of different religions. Mr. Pi was not only following Hinduism rather he looked other religions such as Islam, Christianity. He tried to know the core values of different religions and practices. He did not follow any specific religion but he believe in a God. His father was worried about his strange behavior in the question of God and religions. At the time when Mr. Pi was about sixteen his father decided to emigrate to Canada for future of his children. They sold many lovely animals to different zoos but they wanted to carry some to Canada and sell there. They started their travel by a Japanese cargo ship, Tsimtsum. 


\section{8| Man Bahadur Khattri}

The ship itself had more international environment. In the ship officers were Japanese, crew were Tiwanese and they start sailing from Madras across the Bay of Bengal, down through the Strait of Malacca around Singapore and up to Manila. After four day they left Manila the shipwreck in Pacific Ocean and Mr. Pi is the only human survivor. The weather was terrible, sometimes it was comfortable but in the lifeboat interesting things begins to happen that hyena start eating animals like in a food chain in the ecosystem. The hyena eats first the zebra and then the orangutan. The tiger then eats the hyena, and Mr. Pi feeds the rat to the tiger, trying to keep away from being eaten himself. Pi starts thinking of killing tiger or Richard Parker but he decided to keep him alive, coexist and learn. Richard Parker was a Bengali Tiger. Mr. Pi fed him different sea animals such as fish and Turtle. It became the means of communication and something to do. Mr. Pi fell in love with Richard Parker and start thinking without him Pi would not be able to survive. Eventually, the boat comes ashore in Mexico, where Richard Parker runs off into the Mexican forest left him unceremoniously without looking back. Mr. Pi recounts his tale to the officials of Maritime Department in the Japanese Ministry of Transport, who don't believe his story at first. First they wanted story without animal. They could not believe that a human and a Tiger in a boat for such long time could survive. Mr. Pi argues that tiger exist, lifeboat exist, and ocean exist. He then retells the story, allegorically substituting people for the animals. At last Mr. Okamoto, the Japanese official has said that the story with animal is the better story. Let me briefly contextualize the author, Yann Martel.

\section{TheAuthor: Jann Martel}

Yann Martel is a Canadian however he was born in Spain. Mr Martel was awarded the Man Booker Prize for the Novel, Life of Pi, which is categorized as fantasy and adventurous. His parents both works at the Canadian foreign service. He grew up in different countries like Canada, Costa Rica, France, Spain, and Mexico. He earned a degree in philosophy. He also worked several odd jobs, including tree planter, dishwasher, security guard, and parking lot attendant before turning to writing full-time at the age of twenty-seven. Martel has traveled extensively different places like Iran and Turkey. He has also been to India and spends more than a year. He has written and published several prize winning books: Seven Stories (1993), The 


\section{9| Man Bahadur Khattri}

Facts Behind the Helsinki Roccamatios (1993), Self(1996), Life of Pi (2001), WeAte the Children Last (2004), Beatrice and Virgil (2010). Similarly, his another well-known work is '101 Letters to a Prime Minister: The Complete Letters to Stephen Harper (2012) http:// www.library.nashville.org/NashvilleReads/LifeofPi_AuthorBio Synopsis.pdf). In this context and while analyzing the Novel using human ecological lens we have to be aware of the author's subject as philosophy for the point of knowing that; his travel and grew up in different countries of different ecological settings/landscape, religion, beliefs and socio-cultural practices, family background, his work before he started writing. This is knowing how which has great influence on his perception of nature, socio-cultural relations around the world. The author reflects of his life and thought on nature and culture relationship. In this Novel, his focus is on Nature and God. His faith to God disregards of the different names is expressed in several places. In his introductory writing of Life of Pi, has written that "and it will make me believe in God" (Martel, 2001, p. x). Therefore, he chooses fantasy and adventure as a plot or element, theme, or setting for the Novel.

\section{Diversity and Perception}

The world around us is diverse. We can see different people, culture, social relationship, animal world, plants, ecological zones, time, place, weather, and climatic conditions. Every individual human, place, animal, plant do not only have different appearances but they also have common features. This has made us living possible. Practically diversity is life and conceptually it is the beginning of intellectuality. Human mind searches for the reason why diversity in the world existed. Is diversity necessity for survival of human being and other living beings? Does diversity affect non-living things around us? Most likely, every individual start questioning why that particular thing is different than this one? Despite variability of age in my opinion from child to elderly people we have same way of questioning in diversity, but the way we answer is contextual and relational. According to Kassam (2009, p. 69) "diversity is the foundation of sensory perception and is the basis of knowledge. Perception is achieved by recognition of difference". He further states that sensory organs perceive 'things' to be separate from other 'things.' These 'things' are made real by their relationship with other 


\section{0| Man Bahadur Khattri}

'things.' You can look at a cat and a dog, a black cat and a white cat. Similarly different colors of dogs, size, appearances, but they are dog any way. But our interest goes to the differences. People have selection or preferences. Therefore, diversity is the basis of our consciousness and ultimately makes us human. The United Nation Conference on Environment and Development (UNCED), Rio de Janeiro on 3-14 June 1992 has defined biological diversity as, "variability among living organisms from all sources including, inter alia, terrestrial, marine and other aquatic ecosystems and the ecological complexes of which they are part; this includes diversity within species, between species and of ecosystem" (Secretariat of the Convention on Biological Diversity, 2003, p. 5). The UN convention was concerned about the conservation, sustainable use and the fair and equitable sharing of benefits of biological diversity. In this context conserving cultural diversity having value of protection and harmony with biological diversity is most important otherwise these issues became only slogans of elites. Ryle (1984, p. 26) argues that the human capacity for rigorous theory lay the superiority of men over animals. I agree with Ryle that human being have capacity to conceptualize and express the reality around us in a systematic way. In the Novel, Mr. Pi learned ferocious and dangerous behavior of different animals in relation to animal as cute, friendly, loving, devoted, merry, understanding from his father in his child. Furthermore, wild animals can kill, injure, scratch and bite to other animals as well as human beings. He come to learn that animals also have social rank like human beings as food chain which is clearly shown in the Pacific Ocean when hyena start eating zebra, orangutan, and then tiger eats the hyena. Mr Pi was afraid of being eaten by Richard Parker then he starts feeding tiger with rats, turtle, and fish. Mr. Pi learn that by observing directly or taught by his father to keep him away from animals because he was afraid one day tiger will kill and eat him. Mr. Pi was quite aware, if tiger became hungry then the tiger will eat him anyway. Can we assume that tiger felt the need of human being for its own survival? Does animals with necessity feel the coexistence of other animal such as human for their own survival? We could think that how the plot of Novel would change if the food chain over there followed beginning from Tiger eating human rather than hyena starts eating zebra first? Most probably if a tiger starts eating hyena would not make much difference about the plot of Novel than the eating first human being. 


\section{1| Man Bahadur Khattri}

There are many examples in the life of $\mathrm{Pi}$ about diversity and perception. One of the most important example would be religion. $\mathrm{Mr}$. Pi is around the diverse religious belief especially focuses on Hinduism, Christianity, and Islam. Mr. Pi visits temple, Mosque, and Church. He meets Pandits, Priests, and Muslim Imams. His house is a kind of temple where he can see lord Ganesh, Shiva, Krishna, Laxmi, Shakti, the mother Goddess in the form of Parbati, Hanuman, picture of virgin Marry, picture of black-robed Kaaba, the holiest sanctum of Islam. Similarly, there are Holy books such as Koran and Bible. In this context Mr. Pi compares and contrasts the belief of different religions. For Mr. Pi the Hindus in their capacity of love, are indeed hairless Christian, just as Muslim, in the way they see God in everything, are bearded Hindus, and Christens, in their devotion to God, are hat wearing Muslim (Martel 2001, p. 50). The discussion about religion goes on with his father who says religion is darkness, but in his thinking religion is light. However, he doesn't believe in particular religion but Mr. Pi believes in only in a God despite different names. It was such a context that he loved every religion which he saw many good things, so he could not be in all religions but he turns to be believer of only one God. The interaction among different religious belief and equal respect to all religion has developed his the beliefs in one God not following a specific religion.

Kassam (2009) states that the notion of diversity asserts a pluralistic world - an earth made up of relations between many interacting things. Conservation of diversity is not just an ideal to strive for, but a practical necessity. In fact, in the twenty-first century it is urgent for the survival of humanity and all life on this planet. In this regards, I agree with the statement made by Kassam (2009) because the most important thing in diversity that supports the livelihood of people. Diversity of plants, animals, location and places, culture, social organization, technology are important things for the humanity as a whole. For me destruction of diversity is the destruction of humanity. I argue that homogeneity is static and diversity is dynamic. If we look at global politics today they are fighting for homogeneity, but they speak about diversity. By heart they do not accept diversity or the coexistence of others and they try to kill diversity. In the Novel, "Life of Pi", zoo was taken as 'the source of pleasures and paradise on earth'. It is because even in a small area many different animals of different habitat can be observed their life and you can learn a lot about them. 


\section{2| Man Bahadur Khattri}

However, the animal would like to be free at their habitat. In religious context, different religions can live side by side, on the name of God they work in different way the world becomes diversity of religions and colorful with fares and festivities. The author has effectively used allegory to raise important questions about faith, religion, and meaning.

\section{Relations: Complex Connectivity}

In the Novel Life ofPiwecanunderstand severalcomplex connectivity. The relationships of human being, animals, water and land. We can see the story of Novel lies in land (India), water (Pacific Ocean) and land (Mexico) again. "Life of Pi", in India was with different people who were helping him to teach zoological knowledge as well as spiritual knowledge. In the water or Pacific Ocean Mr. Pi practice the knowledge gained being without human only with wild/furious animal. We can understand how the author has made the relationship of life, death and life. It is interesting that author has not given equal emphasis on human being. The feeling of reading the novel I got that Mr. Pi was worried more for tiger rather than his parents and brother who sank in the ocean. A kind of new relations we can understand that any person who lost own family or neglected from the family start social life with animals. Animals become the nearest and dearest friends for them. Mr. Pi was able to adapt the weather in Ocean, he learned how to live with Richard Parker and sea animals. Sea animals became the source of food for both Mr. Pi and Richard Parker and their survival. Mr. Pi changes his dietary habit form vegetarian to non-vegetarian. The difficult situation as well as inherent capacity in the animal, which Mr. Pi expresses, "animals fight us, it is out of sheer desperation. They fight when they feel they have no other way out" (Martel, 2001, p. 296). This principle was followed throughout the struggle in the ocean. It means that how do behave the animal will also responses accordingly. The human and animal relationship was successfully established because of knowledge and feeling. This builds a kind of interrelatedness.

According to Kassam (2001, p. 3) human ecology describes the relationshipsbetween people and theirhabitat. Itincludes therelations between humans and other animals, plants, and their habitats. Using Human ecological lens he has described interrelatedness with 


\section{3| Man Bahadur Khattri}

harvesting and use of various species of (1) marine mammals, (2) terrestrial mammals, (3) fish, (4) birds, and (5) plants by members of the community of Wainwright. Martel (2001) has tried to bring unity of science and religion or spirituality. We can see complex interconnectivity of religious belief, biodiversity conservation and plant and animals relationship with the subsistence/survival of human being.

\section{Context: Spatial and Temporal}

Context is dynamic and it provides the basis of relationship. Kassam (2009) argues that learning is achieved in a context. Context is understood in two forms: spatial and temporal.Acontext provides the basis of narrative - as a pattern which connects. Meaning is revealed through relationships. Inductive ways of understanding is important and what is the reference as a small fact in the Novel might suggest us to big truths. In human ecology we have to contextualize the research problem in order to illustrate, so people will be able to think, feel and realize how close the researcher is with the problem. Bringing into context also supports to raise questions and answers related to the topics. In the Novel there are several interesting contexts. In India Mr. Pi relationships with parents, mamaji, pandit, and school are important. Where Mr. Pi learnt to swim, believe in God. In the context of ocean thunder, rain, sun, wind, shark, turtles, school of fish all are important. To cope with such situation, crossing all Pacific Ocean Mr. Pi uses the knowledge of his childhood, learns further and prays to the God. In Mexico, he told story what happened and what he experienced in the ocean. Similarly, I can see new relations and challenges are established when someone moves from one place to another Migration of human being is also creating new settlement and relationships with the quality of diversity. We can see at the cities, we find people of diverse religions, colors, cultures. In the context of Novel, zoo becomes setting of diverse animals however we have to think about animal's freedom to live in their habitat. Zoo is artificial habitat for animals. However zoo is cultural institution like public libraries and museum. Politics is also surrounded with the zoo for conservation/protection of animals or business. In the context of religion, the Hindu Pandit were talking about Christianity is outside religion. Furthermore, he brings example of two religions Hinduism and Christianity and symbolize with the river and city. For 


\section{4| Man Bahadur Khattri}

him Hinduism flows like the Gangas and Christianity bustles like Toronto at rush hours.

\section{Phronesis: Knowing that and Knowing How}

Kassam (2009) illustrates that phronesis is practical wisdom. It is marked by reflexive analysis in which cultural values are contributing factors. The Novel is written having influence of different contexts and perception are carried out. It is to communicate own idea to the wider public not to the academics of special field. It has a wider impact in thinking, feeling and acting. He has discussed people's behavior to God and how do they illustrate in different icons and symbols in nature. This is somehow associated with their subsistence. Like the Hindu God Krishna is associated with cow herders and butter. Krishna as a child he ate some dirt and mother asked him to show mouth and Krishna showed to her whole universe in his mouth. The imagination of the world of Hindus (Martel, 2001, p. 56). It also associated with knowing that and knowing how. Knowing that and knowing how are different stages and methods of learning. Kassam (2009) stated that knowing how is embedded in experience - it is contingent. It is gained through performance. Phronesis requires the interaction between the general and the particular, judgment and choice; it is concrete and related to experience. It takes into account the universal through the particular. The process of learning viewed as phronesis is instructive about the process of knowledge generation, acquisition, and application. In this sense any form of knowledge generation, scientific or indigenous, is ultimately context-dependent.

Knowing that and knowing how are important things to consider in social life. The selection of topics, character, plot, words, repetition of some words and phrases in Novel are important. Kassam (2009) has stated that knowledge from a human ecological point of view does not lie in the heads of individuals, but in the relations between them and their environment. Human ecology exemplifies the complex interconnectivity between the biological and cultural relations.

What about animal rights in the zoo, how can we conserve and protect endangered animal species? It is a debate in the world among the conservationists. What is narrated in the Novel that animals in the wild lead life of compulsion and necessity within an unforgiving 


\section{5| Man Bahadur Khattri}

social hierarchy in an environment where the supply of fear is high and the supply of food low and where territory must constantly be defended and parasite forever endured.

Knowing that of Mr. Pi is also associated with the livelihood of people such as his father zoo business, survival in the Ocean, he also has compared snake charmer and his survival in relation with cobra snake. The snake charmers knowledge about snakes bite all related with subsistence and survival. How father of Mr. Pi was trying to teach about animal behavior in the practical sense? Mr. Pi was excellent in Zoology and religion during his study at college, he won all prizes in Zoology. It does not mean that he did not win any prize in religion because there was no prize managed. How did Mr. Pi knowing that the zoological knowledge, we must contextualize knowing how, one of the reason was that he was keen curious about animals and religion and started putting questions of those subjects from his childhood. He tried to get answers from his parents, friends, and religious leader. He wanted to know directly and satisfactorily. He observed the world around him. The unity of theoretical and practical aspect of science develops his knowing that at a higher level. The indigenous knowledge is important and fulfills the inadequacy of scientific knowledge also integrated spiritual knowledge on plants and animals. That spiritual knowledge is the relationship between human being, plants and animals as well as the environment of that particular area. The human ecological knowledge is that which we must focus on it. As far as I understand it is one of the most important aspect of learning in human ecology. On the Ocean, first Mr. Pi was afraid with Hyena, he remembered knowledge from his father, 'when the moon rises that the hyena's day starts and it proves to be a devastating hunter'. Another important thing is that leaning from childhood with parents in different context has much more impact of an individual to the future performance and selection of the subject to study and enjoy.

For Author religion is light and it will save to human beings. Further he says, "there are no grounds for going beyond a scientific explanation of reality and no sound reason for believing anything but our sense experience. A clear intellect, close attention to detail and a little scientific knowledge will expose religion as superstitious bosh. God does not exist" (Martel 2001, P 27). I can see the struggle 


\section{6| Man Bahadur Khattri}

between science and religion. Do they contradict? Does science have religion? If I see religion with rituals, beliefs, norms and values are not these elements in science? We have a problem that we separate them without understanding the co-existence which is absolute like body and mind cannot be separated. This actually reflected to the writing because he has focused his writing on animal. The aspect of humanity in the Novel can also be observed on the international community work in different space, ship, zoo, Canada or in Mexico and trying to help each other. However, the language and culture was not barrier. Mexico people helped Mr. Pi with medicine, warm food, clothes, and homely environment.

Author believes in God and God protects human being. Human being-animal relation is another important topic. Richard Parker and $\mathrm{Mr}$ Pi are the representation of co-existence of animals and human being side by side. It this condition author believes that animals can be protected even in dangerous condition. He has used Hindu religion to demonstrate the co-existence. He brings many references of Hindu Gods associated with animal such as elephant as a symbol of Ganesh, snake as Naga, monkey as Hanuman. They are all respected and worshiped. Many plants are also worshiped and used in different rites, rituals and festivals. They are surrounded their gardens with their necessary presence in their livelihood. This leads them to protect and care. This relationship leads them to protect bio-diversity. Animals are worshiped and people are feared to kill even though they are ferocious and dangerous. The author focuses on ecosystem of nature where one to other species relation in a food chain which forced them to survive on each other for food and sex. He gives example of Rhino and goat. They prefer being together. He illustrates further that different animals have different capacities: cat's look, deer's listen, bear's smell. These different capacities support animal to survival in ecosystem. Therefore, the ecosystem in nature is important to understand the value of diversity in the society and culture. In this regards multi religious, beliefs, identity, languages, knowledge system becomes necessity in any society in the world. Nepali society is peaceful despite all kind of issues of ethnicity, religion, regional disparities raised. Because of their diverse social and cultural settings; they seems to be harmonious among the different people and with plants and animals by taking them into ritual and ceremonial contexts. This is also a kind of harmonizing process world around us 


\section{7| Man Bahadur Khattri}

and developing value of cultural and biological diversity. However this is a successful Novel. The problem in this Novel lies on its focus which is small aspect of human life and tries to advocate larger and complex issues like bio-diversity conservation and world peace. The story is not what common people would face every day in relation to their habitat and survival.

\section{Acknowledgements}

I would like to extend my deepest gratitude to Karim-Aly S. Kassam, Professor at the Department of Natural Resources and American Indian, College ofAgriculture and Life Sciences, Cornell University, USA who taught me human Ecology during Fall Semester 2014.

\section{References}

Kassam, K. S. (2009). Biocultural diversity and indigenous ways of knowing: human ecology in the Arctic. Calgary, Alb.: University of Calgary Press.

Kassam, K. S. (2001). Passing on the knowledge: mapping human ecology in Wainwright, Alaska. Calgary: Arctic Institute of NorthAmerica.

Martel, Y(2001). Life of Pi: a novel. New York: Harcourt.

LifeofPi_AuthorBio_Synopsis:http://www.library.nashville.org/ NashvilleReads/LifeofPi_AuthorBio_Synopsis.pdf.

Ryle, G. (1984).The concept of mind. University of Chicago Press ed. Chicago: University of Chicago Press.

Secretariat of the Convention on Biological Diversity. (2003).

Handbook of the Convention on Biological Diversity: Montreal, Quebec, Canada: Secretariat of the Convention on Biological Diversity. 